\title{
Distribution and ecological aspects of Rhodnius pallescens in Costa Rica and Nicaragua and their epidemiological implications
}

\author{
Rodrigo Zeledón/ ${ }^{+}$, Francisca Marín*, Nidia Calvo** , Emperatriz Lugo*, Sonia Valle*
}

Escuela de Medicina Veterinaria, Universidad Nacional, Apartado Postal 86, Heredia, Costa Rica *Programa de Enfermedad de Chagas, Ministerio de Salud, Managua, Nicaragua **Instituto Costarricense de Investigación y Enseñanza en Nutrición y Salud, Tres Ríos, Cartago, Costa Rica

In light of the Central American Initiative for the control of Chagas disease, efforts were made on the part of Costa Rican and Nicaraguan teams, working separately, to determine the present status of Rhodnius pallescens in areas close to the common border of the two countries, where the insect has appeared within the last few years. The opportunity was also used to establish whether R. prolixus, a vector present in some areas of Nicaragua, has been introduced in recent years into Costa Rica with Nicaraguan immigrants.

It became evident that wild adults of $\mathrm{R}$. pallescens are common visitors to houses in different towns of a wide area characterized as a humid, warm lowland, on both sides of the frontier. Up to the present, this bug has been able to colonize a small proportion of human dwellings only on the Nicaraguan side. There was strong evidence that the visitation of the adult bug to houses is related to the attraction of this species to electric lights.

There were no indications of the presence of R. prolixus either in Nicaragua or in Costa Rica in this area of the Caribbean basin. Triatoma dimidiata, a widespread domestic species in both countries, was totally absent in the explored areas of Costa Rica but occasionally occurs on the Nicaraguan side.

Serological surveys in children of both areas showed that transmission of Chagas disease takes place in a rather small degree in Costa Rica and more commonly in Nicaragua, indicating that R. pallescens could be a potential threat as a vector in this particular region.

Key words: Rhodnius pallescens - Rhodnius prolixus - visitation - Chagas disease - Costa Rica - Nicaragua

Rhodnius pallescens was first reported as existing in Costa Rica from adult specimens captured inside houses: two females from the northern part of the province of Alajuela and one male from the province of Limón (Marín $\&$ Vargas 1986). More recently it was found again in areas of the same two provinces, and 29 specimens ( 20 females and 9 males) were recorded while attracted by light traps in at least three biological stations by the National Biodiversity Institute (Zeledón et al. 2001). Furthermore, the species has been found in palm trees (Attalea butyracea) in an area near the Nicaraguan border and some of the specimens were infected with Trypanosoma cruzi (Zeledón et al. unpublished data).

In Nicaragua the species was not known but within the last few years it has been found and recorded as a common visitor in poor houses of the Department of Rio San Juan, in areas close to the Costa Rican bounder (Marín 2003).

According to Lent and Wygodzinsky (1979) the established distribution of the species includes Belize, Panama, and Colombia. It has also been reported as present in the Amazon area of Venezuela (Ramírez-Pérez 1987)

This study was carried out on both sides of the central part of the border of Costa Rica and Nicaragua. The main aims of the Costa Rican team were: (a) to establish the possible colonization of houses by $R$. pallescens; (b)

+Corresponding author: rodrigozeledon@ice.co.cr Received 11 October 2005

Accepted 30 January 2006 to determine the possibilities that $R$. prolixus could have been established in the area; and (c) to search for Triatoma dimidiata, the main vector of Chagas disease in the country, in or around houses. In the case of the Nicaraguan group the main purpose was to determine the presence of $R$. prolixus in places close to Costa Rica and the possibility of its transport to the Costa Rican territory by Nicaraguan immigrants. All the work was done under the objetives and indications established by the Central American Initiative for the control of Chagas disease.

\section{MATERIALS AND METHODS}

Study areas - In Costa Rica the chosen areas were: the village of Santa Cecilia within the district of El Amparo and the settlement of Tablillas in the district of Los Chiles, both belonging to Los Chiles county, Alajuela province, latitude $10^{\circ} 51^{\prime} \mathrm{N}$ and longitude $84^{\circ} 42^{\prime} \mathrm{W}$ the former, and $11^{\circ} 11^{\prime} \mathrm{N}$ and $84^{\circ} 42^{\prime} \mathrm{W}$ for the latter, which is located about $5 \mathrm{~km}$ from the Nicaraguan boundary. The altitudes are 44 and $43 \mathrm{~m}$ above sea level, respectively. The climate is warm and humid in the region with a mean temperature of $26^{\circ} \mathrm{C}$ $\left(21-30^{\circ} \mathrm{C}\right)$ and a mean annual rainfall of $2627 \mathrm{~mm}(1979-$ 2001) with three months of less precipitation (February to April).

In Nicaragua the survey was part of a base-line entomological study about the dispersion of $R$. prolixus and $T$. dimidiata in the entire country, under the responsibility of the Ministry of Health. Part of this survey was done in the Department Rio San Juan, between $11^{\circ} 41^{\prime}$ to $41^{\circ} 0^{\prime} \mathrm{N}$ and $84^{\circ} 54^{\prime}$ to $84^{\circ} 32 \mathrm{~W}$. The climate and the rainy pattern is similar to that described for the Costa Rican side and the altitudes varies from 40 to $180 \mathrm{~m}$. 
Procedure - In Santa Cecilia, where R. pallescens had been detected before as a visitor to households, we surveyed 50 houses; in Tablillas 30 houses dispersed along the only road that goes to the border were searched. Five well trained senior or graduate university students were responsible for the survey.

In Nicaragua, 2000 houses from the Department Rio San Juan, close to the river of the same name, which separates the two countries, were surveyed for the presence of triatomines and sprayed with insecticide. Villages in six municipalities belonging to the Department were surveyed. The municipalities are: El Almendro, Morrito, San Miguel, San Carlos, El Castillo, and San Juan del Norte, all of them located in the eastern part of the Lake of Nicaragua in the Caribbean basin (Fig. 1).

The search in both countries was made by the man/ hour method using at least two team members for a minimum of $15 \mathrm{~min}$, assisted by forceps and flashlights.

Serological surveys were also carried out in the study areas. In the case of Costa Rica, in 811 children (397 girls and 414 boys), mostly 7 to 12 years old (9\% were over 13 years) belonging to 26 randomly selected schools, from Los Chiles county. Two commercial ELISA tests (crude and recombinant antigens from Wiener) were used for the screening and two more tests were employed for confirmation (IHA, IIF). The Nicaragua survey was performed in 665 school children ( 335 girls and 330 boys), 7 to 14 years old, from 37 schools, using Wiener's ELISA test with crude antigen, as part of the campaign of the Ministry of Health for the control of the vectors of Chagas disease.

\section{RESULTS}

In Santa Cecilia, households are separated from each other by extensive open yards. Most houses presented the typically peridomiciliary ecotopes (wood pieces, fire wood, store rooms, chicken coops) that serves as refuge for $T$. dimidiata in other areas of the country (Zeledón 1981) but no insects were found in the 50 houses searched. When dried specimens of $T$. dimidiata were shown to the householders, and also to the children of the neighboring schools, no one recognized them, whereas several persons admitted to having seen insects identical to the Rhodnius sample. One male and one female of $R$. pallescens were captured by the inhabitants inside their respective houses and were given to us.

In Tablillas the houses are poorer and occupied mainly by Nicaraguan immigrants (73\%); $17 \%$ of the houses searched had palm thatch, and firewood and chicken coops were common. The inhabitants did not recognize either $T$. dimidiata or Rhodnius with the exception of a family that had seen the later in Nicaragua. $R$. pallescens is not a visitor of the huts as it is in Santa Cecilia, which is probably explained by the lack of electric lights.

We also received $R$. pallescens adults in addition to Santa Cecilia, from the town of Los Chiles and from some southern districts such as Santa Rosa (Pocosol), Cutris, and Santa Clara (Florencia), all in San Carlos county (Figure).

The serological survey in Los Chiles revealed two 11 year old girls positive for a prevalence of $0.24 \%$.

In Nicaragua, $R$. pallescens was found in 37 villages belonging to the six municipalities that make up the Department Rio San Juan. Details of these findings will be reported elsewhere (Marin et al., unpublished data) (Figure).

In most of these places, in clear contrast with the situation in Costa Rica, $R$. pallescens was occasionally associated with T. dimidiata. A total of 58 specimens of the latter species was found in 32 houses and 52 were adult insects probably coming from nearby forests.

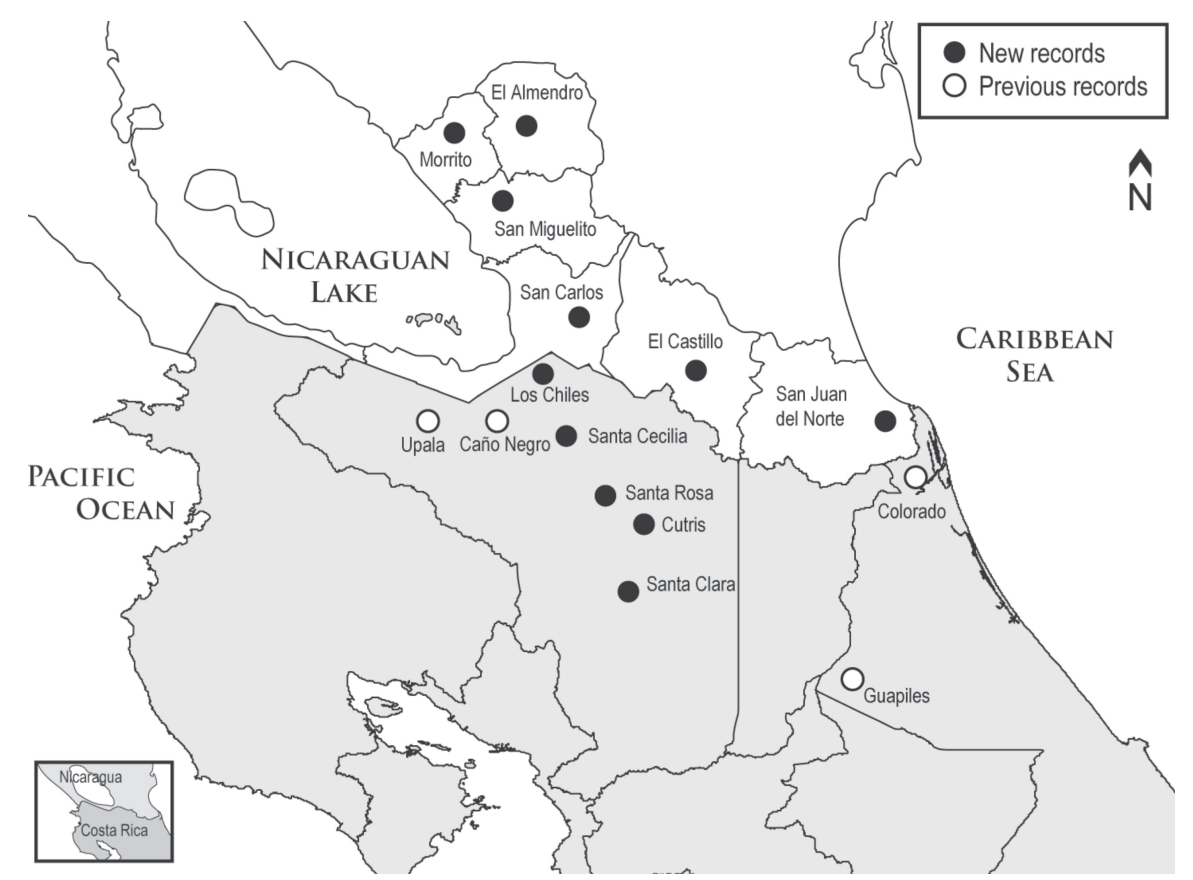

Partial map of Nicaragua and Costa Rica showing the border of both countries and the continuous distribution of Rhodnius pallescens. 
From a total of $78 R$. pallescens found in or around 34 houses, 5 were nymphs corresponding to 4 households (4 of 5th instar and one of 3rd). The insect was scarce, one or two per house, but in at least three houses groups of five were found: in one case (El Almendro, Villa Alvarez) they were in a fire wood pile in the peridomestic space; in another case (San Miguel, El Ojoche), they were in the bed of the dormitory and one of them was a 5 th instar nymph; and in the third case (San Carlos, Melchorita), the insects were also in one bed. Of these insects, 25 were captured inside houses and 12 were outside; the rest were not recorded as to the place they were found or were given to us by the inhabitants. Males and females appear in a similar proportion, 30 and 28 respectively (15 were not identified by sex). The main places where the insects were found inside dwellings were: beds, walls, and palm roofs; and outdoors were: firewood and stored palms. Of 43 adult insects examined for T. cruzi infection, 18 were positive (41.9\%).

The serological survey yielded 45 reactive cases $(6.7 \%)$ distributed as follows: 7 cases from El Morrito, 20 cases from San Carlos, 16 cases from El Castillo, and 2 cases from San Juan del Norte.

\section{DISCUSSION}

During the survey for triatomines in the north central part of Costa Rica (Alajuela province) near the border with Nicaragua, we obtained evidence of the complete absence of $T$. dimidiata and $R$. prolixus in the area and of the presence of adult $R$. pallescens as a common visitor to houses. Even the workers of the Malaria Department of the Ministry of Health, assured us that they have never seen the first two species in the entire region.

Since $T$. dimidiata was not present among the species captured in light traps located in the area of Caño Negro, very close to the town of Los Chiles, it was not surprising we did not find it colonizing houses in the zone (Zeledón et al. 2001).

$R$. prolixus was not found in the Department of Rio San Juan of Nicaragua from where most of the immigrants enter Costa Rica by boat on the Frio River. This might be the reason why this species has not been introduced through this area as it was several decades ago by the interAmerican highway on the Pacific western side (Ruíz 1953).

R. pallescens seems to be an important species in this area, on both Costa Rican and Nicaraguan sides. Despite being a frequent visitor on the Costa Rican side, there is still no evidence of colonization of houses by this species. Nevertheless, this visitation by adult bugs might acquire more epidemiological significance in this region in the future, and its recent finding as a common inhabitant of palm trees (Attalea butyracea) reinforces this idea (Zeledón et al., unpublished data). On the other hand, in Department Rio San Juan, Nicaragua, the species seem to be even more common than it is on the Costa Rican side, and the finding of a few nymphs either in peridomestic or domestic places in four households, indicates that the species is already colonizing human dwellings. Moreover, it has been proved very recently that the species also inhabits the same palm tree as in the Costa Rican side
(Marin et al., unpublished data). The fact that the species has been found infected with $T$. cruzi in both countries should also be kept in mind.

The finding of two acute cases of Chagas disease in 1987, in two children from the same house in Pocosol of San Carlos, Costa Rica, where T. dimidiata does not exist, suggests that these cases acquired it from visiting $R$. pallescens (Dr JM Ruíz Medical Director of the Pocosol Clinic, pers. commun.). Also, the two chronic cases detected by serology and reported here, in children who have never been out of the area, is further indication of local transmission, probably by this species. A few wild adult Panstrongylus geniculatus have been captured in this area of Costa Rica (Zeledón et al. 2001) and only a few specimens of this species are known in the Department Rio San Juan, Nicaragua (Marin et al., unpublished data).

The situation in the Nicaraguan area seems to be epidemiologically different and the transmission there might be due to both $R$. pallescens and $T$. dimidiata. This could explain the higher serological prevalence rate of infection in this country.

Our findings of $R$. pallescens existing in lowlands (less than $400 \mathrm{~m}$ ), coincide with what has been reported before (Galindez et al. 1996). Also, the high relative humidities of the areas where the species is found is in accordance with the stenohydric status of this species, being unable to thrive in relative humidities lower than $60 \%$ (Zeledón 1974, Jurberg \& Rangel 1984).

In Panama, R. pallescens has been found both under domestic and sylvatic conditions, and Pipkin (1968) did an extensive study during a three-year period, in rural communities of three provinces of central Panama. The author made clear that this species frequently colonizes different places inside households, including cracks in the walls, beds, hanging clothes and thatch roofs. He was able to capture a total of 3257 specimens which represented $99.18 \%$ of the entire collection (a few adults of other species of triatomines were also found). All stages of development were found including eggs which were often attached to the thatched roofs, and $32.7 \%$ of a sample of these domiciliary bugs was infected with $T$. cruzi. In Pipkin's study $R$. pallescens was also found in peridomiciliary pig pens and chicken coops, and in wild habitats such as opossum nests.

The colonization of $R$. pallescens was confirmed by the finding of 807 specimens in La Chorrera, Central Panama, including nymphs and adults, in or around human dwellings. Some of them were infected by $T$. cruzi and T. rangeli (Sousa \& Johnson 1973).

More recently, Vásquez et al. (2004) have observed a marked decrease in human dwelling colonization by this species, probably due to an evident house improvement in some areas of Panama.

The distribution of the bug in Panama extends from the eastern region of Darien, in the Caribbean basin, including the provinces of Panama, Colon, and Darien, to the province of Bocas del Toro in the western region, close to the border with Costa Rica (Sousa 1972).

Whitlaw and Chaniotis (1978) were able to capture $R$. pallescens in light traps on both the Pacific and in Caribbean sides of Panama, and all stages were common in 
palm trees of the species Scheelea zonensis $(=A$. butyracea). The frequency of the bugs in this sylvatic ecotope, led the authors to believe that there is a close relation between Chagas disease and the practice of using the fronds of this palm as thatch.

Christensen et al. (1980) extended some of these observations by analyzing the blood of the stomach content of $200 R$. pallescens nymphs found in palm trees. These bugs showed a variety of hosts, opossum being the most common, followed by anteater and sloth. In another experiment, Christensen and Vásquez (1981) examined domestic/peri-domestic and wild bugs finding, this time, that human blood was present in more than half of the 1303 insects tested, including those found in palm trees and bird nests. The second and third most common sources of blood were opossum and bird, respectively. In view of these findings the authors suggested a two way migratory behavior of both nymphs and adults, from neighboring palm trees and bird nests to houses.

In Colombia, the presence of $R$. pallescens associated with human dwellings was noticed rather recently and it appears that most of the time mainly adult insects are encountered under peridomiciliary conditions and occasionally some nymphal stages. Colonies of the insect are also found in sylvatic ecotopes such as the crowns of at least four species of palms: Attalea butyracea, Coccus nucifera, Jessenea batava, and Elaeis oleifera (Moreno et al. 1992, Moreno \& Jaramillo 1996, Jaramillo et al. 2000). The species has a wide geographical distribution in the country and is considered a potential problem as a candidate to replace the domestic $R$. prolixus after the latter is eliminated from houses as a consequence of control campaigns (Jaramillo et al. 2000).

The latter authors contradict the findings obtained by Pipkin (1968), who classified it as a "tardy defecator", by considering this species, to be a highly competent vector, in the laboratory, "equally or more effective than $R$. prolixus to transmit $T$. cruzi", by being capable of defecating while still in contact with the host and by achieving high rates of infection (Moreno \& Agudelo 1992, Moreno et al. 1992, Jaramillo et al. 2000).

Pizarro-Novoa and Romaña (1998) found $1356 R$. pallescens in $86 \%$ of A. butyracea palms in a dry forest located in the Department of Sucre, Colombia, on the Caribbean coast. They showed no significant differences between the number of insects captured during the rainy and the dry seasons and this is probably due to the microclimate produced in the base of the fronds of the palms. Romaña et al. (1999) reported finding 573 more specimens of $R$. pallescens in the same region of Colombia in four species of palm trees: A. butyracea, C. nucifera, E. oleifera, and Copernicia tectorum, confirming that it is by far more common in the first species of palm.

In conclusion, the present situation in Costa Rica and Nicaragua indicates that $R$. pallescens is a species commonly found wild in a wide area with humid and warm climate, corresponding to the tropical rain forest life zone, where adults are common visitors to households. Nevertheless, the species is showing some trends toward colonizing human dwellings at least in Nicaragua. The possibility that $R$. pallescens could become better adapted to domestic conditions in the near future poses a potential threat in areas as the ones mentioned here and this fact should be kept in mind by the public health authorities of both countries. Furthermore, transmission of Chagas disease in these places by visiting adult bugs seems to be already occurring as indicated by the serological results presented here.

\section{ACKNOWLEDGEMENTS}

To Mrs Carmen Flores, Mr Carlos Picado, Miss Yahaira Rojas, Miss Miriam Tejada, and Miss Eylen Zúñiga for the valuable help during the field work. To Mrs Andrea Blanco for performing the serological reactions and Mrs Ana Lorena Vargas from Inciensa, for clerical help. To Dr Hazel Mairena head of the Clinical Laboratory at Los Chiles Hospital and Dr José Manuel Ruíz, Medical Director of the Social Security Clinic in Pocosol, San Carlos, for their timely help in the working area. To the technicians of the Vector Control Unit and to the epidemiologists of the Primary Health Care Units of Rio San Juan Department, for their valuable field work and to the Medical Entomology personnel of CNDR/MINSA of the Ministry of Health of Nicaragua. To Dr Paul Hanson, from the School of Biology, University of Costa Rica for revision of the manuscript.

\section{REFERENCES}

Christensen HA, Vásquez AM 1981. Host feeding profiles of Rhodmius pallescens (Hemiptera: Reduviidae) in rural villages of Central Panama. Am J Trop Med Hyg 30: 278-283.

Christensen HA, Whitlaw JT, Chaniotis BN, Vásquez AM 1980. Sylvatic hosts of Rhodnius pallescens (Hemiptera: Reduviidae) nymphs in the Panama Canal Zone. J Med Entomol 17: 182 .

Galindez I, Curto de Casas SI, Carcavallo RU, Jurberg J, Mena Segura CA 1996. Geographical distribution and alti-latitudinal dispersion of the tribe Rhodniini (Hemiptera, Reduviidae, Triatominae). Entomol Vect 3: 3-20.

Jaramillo N, Schofield CJ, Gorla D, Caro-Riaño H, Moreno J, Mejía E, Dujardin JP 2000. The role of Rhodnius pallescens as a vector of Chagas disease in Colombia and Panama. Res Rev Parasitol 60: 75-82.

Jurberg J, Rangel EF 1984. Ciclo biológico de Rhodnius pallescens Barber, 1932 (Hemiptera, Reduviidae, Triatominae) em laboratório. Mem Inst Oswaldo Cruz 79: 303-308.

Lent H, Wygodzinsky P 1979. Revision of the Triatominae (Hemiptera, Reduviidae) and their significance as vectors of Chagas' disease. Bull Am Mus Nat Hist 163: 123-520.

Marin F 2003. Control of Rhodnius prolixus in Nicaragua. In Reunión Internacional para el establecimiento de criterios de certificación de la eliminación de Rhodnius prolixus (Stal, 1859), Guatemala, 5-7 Mar 2003, OPS-OMS, JICA, p.1516

Marín RE, Vargas M 1986. Rhodnius pallescens (Hemiptera: Reduviidae) in Costa Rica. J Med Entomol 23: 333.

Moreno J, Agudelo P 1992. Estudio de la capacidad vectorial de Rhodnius prolixus (Stal, 1859) y Rhodnius pallescens (Barber, 1932) con dos cepas colombianas de T. cruzi. Rev Asoc Colombiana Cienc Biol 6: 23-32.

Moreno J, Jaramillo NO 1996. Estudios epidemiológicos sobre la enfermedad de Chagas en los Departamentos de Antioquia, Sucre y Tolima, Colombia. In CF Schofield, JP Dujardin, J 
Jurberg (eds), Proc Intl Workshop on Population Genetics and Control of Triatominae. Santo Domingo de los Colorados, Ecuador, 24-28 Sept 1995, p. 27.

Moreno J, Jaramillo N, Lages-Silva E, Ramírez LE 1992. Biological study of Trypanosoma cruzi and $T$. rangeli in the Magdalena Valle and Antioquia, Colombia. Mem Inst Oswaldo Cruz 87 (Suppl. II): 216.

Pipkin AC 1968. Domiciliary Reduviid bugs and the epidemiology of Chagas' disease in Panama (Hemiptera: Reduviidae: Triatominae). J Med Entomol 5: 107-124.

Pizarro-Novoa JPC, Romaña C 1998. Variación estacional de una población silvestre de Rhodnius pallescens Barber, 1932 (Heteroptera: Triatominae) en la costa caribe colombiana. Bull l'Inst Franç d'Etud Andines 27: 309-325.

Ramírez-Pérez J 1987. Revisión de los triatóminos (Hemiptera, Reduviidae) en Venezuela. Bol Dir Malariol San Ambient 27: 118-146.

Romaña CA, Pizarro JC, Rodas E, Guilbert E 1999. Palm trees as ecological indicators of risk areas for Chagas disease. Trans $R$ Soc Trop Med Hyg 93: 594-595.

Ruíz H 1953. Rhodnius prolixus en Costa Rica. Rev Biol Trop 1: 239-240.
Sousa OE 1972. Anotaciones sobre la enfermedad de Chagas en Panama. Frecuencia y distribución de Trypanosoma cruzi y Trypanosoma rangeli. Rev Biol Trop 20: 167-179.

Sousa OE, Johnson CM 1973. Prevalence of Trypanosoma rangeli in triatomines (Hemiptera: Reduviidae) collected in the Republic of Panama. Am J Trop Med Hyg 22: 18-23.

Vásquez AM de, Samudio FE, Saldaña A, Paz HM, Calzada JE 2004. Eco-epidemiological aspects of Trypanosoma cruzi, Trypanosoma rangeli and their vector (Rhodnius pallescens) in Panama. Rev Inst Med Trop São Paulo 46: 217-222.

Whitlaw JT, Chaniotis BN 1978. Palm trees and Chagas' disease in Panama. Am J Trop Med Hyg 27: 873-881.

Zeledón R 1974. Los vectores de la enfermedad de Chagas en América. In Simposio Internacional sobre enfermedad de Chagas, Buenos Aires, Argentina, Dic.1972, p. 327-345.

Zeledón R 1981. El Triatoma dimidiata (Latreille, 1811) y su Relación con la Enfermedad de Chagas, UNED, San José, Costa Rica, 146 pp.

Zeledón R, Ugalde JA, Paniagua LA 2001. Entomological and ecological aspects of six sylvatic species of triatomines (Hemiptera, Reduviidae) from the collection of the National Biodiversity Institute of Costa Rica, Central America. Mem Inst Oswaldo Cruz 96: 757-764. 